\title{
ANALISIS BEBAN KERJA PEGAWAI DI SEKSI VERSAIGAMONANG DEVISI DEPRODUGAMONANG PERUM PERURI KARAWANG
}

\author{
${ }^{1}$ Kusnadi, ${ }^{2} \cdot$ Yusup Abdul Jaelani \\ 1,2. Program Studi Teknik Industri, Fakultas Teknik, Universitas Singaperbangsa Karawang \\ 1.tikuk.kusnadi@yahoo.com,_2.yusupabduljaelani@gmail.com
}

\begin{abstract}
A b s trak
Penelitian membahas dan menganalisis kesesuaian antara beban kerja pada divisi Verifikasi Uang logam di Deprodugamonang. Metode yang digunakan dalam penelitian ini adalah dengan pengamatan work sampling, uji keseragaman data dari nilai presentase produktif pekerjaan, tingkat ketelitian pengamatan dan analisa perhitungan beban kerja. Hasil uji keseragaman data dari nilai presentase produktif pekerjaan menunjukan rata - rata 70,4\%, 69,54\% dan 73,18\% dengan tingkat ketelitian pengamatan $\pm 8,5 \%, \pm 8,6 \%$ dan $\pm 8,1 \%$ sedangkan hasil beban kerja setiap operator adalah 1,86\%, 2,58\%, dan 1,97\%.

Kata Kunci : Work Sampling, Beban Kerja, Tenaga Kerja.
\end{abstract}

\section{PENDAHULUAN}

Sejalan dengan visi dan misi perusahaan serta dalam era globalisasi, manajemen menyusun strategi perusahaan agar lebih kompetitif secara internasional untuk menjadi Perusahaan Kelas Dunia (World Class Company). Perum PERURI khususnya Departemen Produksi Uang Logam Dan Logam Non Uang membuat strategi agar order dapat terpenuhi dalam mencapai tujuan perusahaan. Agar dalam laju pertumbuhan perusahaan tersebut diupayakan agar selalu meningkat sesuai dengan meningkatnya revenue.

Kebutuhan sumber daya manusia (SDM) semakin meningkat baik dari segi kualitas maupun kuantitas. Untuk mendapatkan SDM yang sesuai dengan kebutuhan perusahaan maka dibutuhkan pengukuran beban kerja sehingga karyawan dapat optimal dalam menjalankan pekerjaannya.

Untuk menghadapi persaingan yang semakin kompetitif perusahaan membutuhkan kualitas SDM yang memiliki kompetensi tinggi. Kinerja suatu sistem kerja ditentukan oleh performansi dari pekerjanya yaitu tingkat keefektifan pekerja menyelesaikan pekerjaannya. Oleh karena itu dibutuhkan suatu metode untuk menghitung tingkat keefektifan tersebut, salah satu caranya dengan melakukan sampling pekerjaan ( metode work sampling ).

Berdasarkan latar belakang diatas, maka peneliti merumuskan masalah sebagai berikut: Apakah terdapat pengaruh beban kerja karyawan terhadap kinerja karyawan di departemen Produksi uang logam dan non uang logam (Deprodugamonang) section verifikasi uang logam?

Tujuan penelitian ini adalah untuk menganalisis kesesuaian antara beban kerja dengan melakukan pengukuran dengan metode work sampling dan memberikan rekomendasi alternatif solusi mengenai beban kerja pada divisi Verifikasi Uang logam di Deprodugamonang Perum Peruri. Penelitian yang dilakukan di Perum Peruri Percetekan Uang Republik Indonesia (PERURI), khususnya Departemen Produksi Uang Logam Dan Non Uang Logam yang berlokasi di Desa Parung Mulya Kabupaten Karawang Jawa Barat 41361. Ruang lingkup penelitian ini yaitu untuk mengetahui tingkat beban kerja karyawan sedangkan lama penelitian yang akan dilakukan adalah 1 (satu) bulan.

\section{METODE PENELITIAN}

Metode penelitian analisis beban kerja adalah proses untuk menetapkan jumlah jam kerja (manhours) yang dibutuhkan untuk menyelesaikan beban kerja dalam durasi waktu tertentu. Analisis beban kerja bertujuan untuk menentukan beberapa jumlah pekerja yang dibutuhkan untuk 
menyelesaikan suatu pekerjaan dan beberapa beban yang dapat dilimpahkan kepada suatu orang pekerja. Penelitian ini dimulai dengan melakukan analisis pekerjan pada divisi verifikasi uang logam di deprodugamonang Perum Peruri. Data diperoleh melalui wawancara terbuka, observasi dan metode work sampling. Penelitian pendahuluan digunakan untuk mengetahui situasi dan kondisi yang diciptakan oleh perusahaan untuk kelancaran dalam melaksanakan pekerjaan. Dalam hal ini penelitian dilakukan sebagai berikut : a. Mengamati lingkungan kerja dan fasilitas yang diberikan perusahaan kepada para operator. b. Mengumpulkan data mengenai deskripsi pekerjaan operator verifikasi uang logam, sehingga dapat diketahui elemen kegiatan produktif dan non produktif. Menentukan waktu pengamatan, pengamatan dilakukan pada jam kerja shift satu, dimana operator masuk jam 07.45 hingga 16.00, dengan waktu istirahat selama 30 menit. Interval waktu pengamatan terhadap pekerja verifikasi uang logam yang dilakukan adalah 10 menit. Hal ini dilakukan dengan asumsi 10 menit adalah waktu rata - rata bagi pekerja menyelesaikan pekerjaanya.

Jumlah jam kerja per hari $=8$ jam $=480$ menit.

Jumlah kunjungan maksimal $=\frac{480}{10}=48$ kunjungan.

Jumlah kunjungan $\quad=\frac{2}{3} \mathrm{x}$ jumlah kunjungan maksimal

$=\frac{2}{3} \times 48=32$ kunjungan per hari

Kunjungan dilakukan selama lima hari, yaitu hari senin, selasa, rabu, kamis dan jumat.

Memilih Operator, pengamatan dilakukan terhadap tiga orang operator verifikasi uang logam, masing - masing pengamatan dilakukan selama lima hari. Beberapa kriteria operator verifikasi yang akan diamati adalah :

a. Operator verifikasi berjenis kelamin laki - laki dan dalam keadaan tujuan yang sehat.

b. Kecepatan kerja normal.

c. Mampu bekerja sesuai dengan deskripsi pekerjaan dan telah bekerja selama 2 tahun.

Menentukan alat penelitian beberapa alat penelitian yang digunakan untuk memudahkan pengamatan dan pencatatan objek berupa lembar pengamatan work sampling, papan dan alat tulis. Metode pengumpulan data Metode pengumpulan data yang digunakan dalam laporan kerja praktek ini adalah

a. Observasi langsung yaitu teknik pengumpulan data yang diambil secara langsung pada objek yang diteliti

b. Teknik wawancara yaitu teknik pengumpulan data yang dilakukan dengan cara melakukan wawancara dan memperoleh penjelasan mengenai data - data yang diambil yangberhubungan dengan topik kerja praktek yang diambil.

c. Studi pustaka yaitu teknik pengumpulan dan pengolahan datayang berasal dari buku - buku yang berhubungan dengan objek yang diteliti.

Metode pengolahan data yang digunakan untuk menentukan besarnya nilai beban kerja operator melalui work sampling adalah :

a. Melakukan uji keseragaman data dari nilai presentase produktif pekerjaan yang teramati.

b. Menentukan jumlah pengamatan yang diperlukan

c. Menentukan faktor penyesuaian dan kelonggaran yang dibutuhkan karyawan untuk menyelesaikan pekerjaannya.

d. Menghitung waktu siklus, waktu normal, waktu baku,dan beban kerja.

Metode analisa data dalam penelitian ini adalah sebagai berikut : Analisa kuantitatif bibuat berdasarkan hasil perhitungan dengan menggunakan rumus dan dinyatakan dalam bentuk angka. Analisis kuantitatif ini meliputi : pengujian keseragaman data, jumlah pengamatan yang diperlukan, tingkat keyakinan dan analisa perhitungan beban kerja operator verifikasi uang logam. Analisa kualitatif bibuat berdasarkan pendapat atau persepsi yang tidak dinyatakan dalam bentuk angka. Analisis kualitatif ini meliputi: faktor yang mempengaruhi beban kerja, kelonggaran dan usaha meningkatkan dan usaha untuk meningkatkan kualitas operatorverifikasi. 
Diagram alur penelitian diperlihatkan dalam Gambar 1. Dan secara garis besar dijelaskan sebagai berikut:

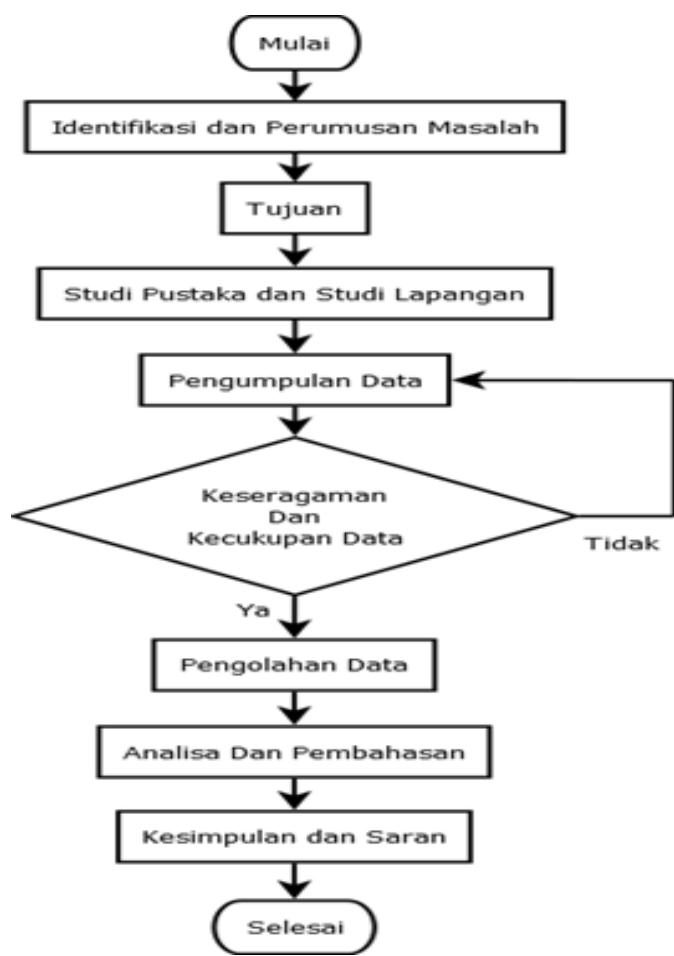

Gambar 1. Diagram alur penelitian

\section{HASIL DAN PEMBAHASAN}

A. Hasil Persentase Produktif Operator "A".

Tabel 1. Persentase Produktif Operator "A".

\begin{tabular}{|c|c|c|c|c|c|c|}
\hline \multirow{2}{*}{ kegiatan } & \multicolumn{5}{|c|}{ Frekuensi pada hari - } & \multirow{2}{*}{ jumlah } \\
\hline & 1 & 2 & 3 & 4 & 5 & \\
\hline produktif & 33 & 30 & 33 & 29 & 30 & 155 \\
\hline Non produktif & 11 & 14 & 11 & 15 & 14 & 65 \\
\hline jumlah & 44 & 44 & 44 & 44 & 44 & 220 \\
\hline $\begin{array}{l}\text { Persentase } \\
\text { produktif }\end{array}$ & $75 \%$ & $68 \%$ & $75 \%$ & $66 \%$ & $68 \%$ & \\
\hline
\end{tabular}

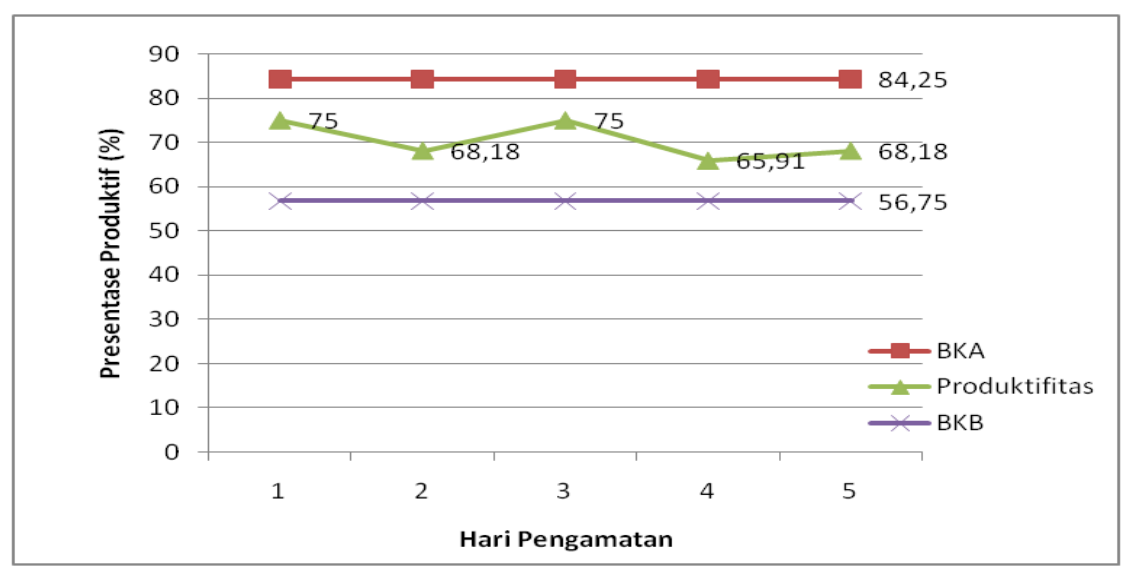

Gambar 2. Peta Kendali Produktif Operator "A" 
Data persentase produktif seluruhnya terdapat diantara batas kendali atas ( BKA ) dan batas kendali bawah ( BKB ), yang menandakan adanya keseragaman data. Hal ini disebabkan tidak adanya penyebab kesalahan umum ( common cause atau change cause) atau sebab khusus ( assignable cause ). Penyebab kesalahan umum misalnya naik turun kondisi kerja dan yang termasuk sebab khusus misalnya kesalahan operator.

Jumlah pengamatan yang diperlukan untuk tingkat ketelitian $10 \%$ dan keyakinan $95 \%$ diketahui melalui rumus berikut :

$$
\begin{aligned}
& \mathrm{S} p=2 \sqrt{\frac{p(1-p)}{N}} \\
& 0,1 p=2 \sqrt{\frac{p(1-p)}{N}} \\
& \text { Sehingga } \quad\left(\frac{0,1}{2} p\right)^{2}=\frac{p(1-p)}{N} \\
& \frac{0,01}{4} p^{2} N=p(1-p) \\
& \mathrm{N}=\frac{p(1-p)}{0,01 / 4 p 2} \\
& \mathrm{~N}=\frac{400(1-p)}{p}
\end{aligned}
$$

Dimana $: \mathrm{p}=\frac{155}{220} x 100 \%=70,45 \%$

$$
\text { Maka }: \mathrm{N}=\frac{400(1-0,7045)}{0,7045}=168 \text { kali kunjungan }
$$

Jumlah pengamatan yang diperlukan untuk mengamati kegiatan operator "A" verifikasi uang logam dibagian perhitungaan dan pembungkusan awal sebanyak 168 kali kunjungan, sedangkan jumlah pengamatan yang telah dilakukan sebanyak 220 kali kunjungan. Hal ini menandakan bahwa jumlah pengamatan telah mencukupi, sebab sudah melebihi jumlah pengamatan yang diperlukan.

Setelah pengamatan telah mencukupi, selanjutnya menentukan apakah hasil pengamatan tersebut sesuai dengan tingkat ketelitian yang diinginkan melalui perhitungan berikut :

$$
\begin{aligned}
& \mathrm{S} p=2 \sqrt{\frac{p(1-p)}{N}} \\
& 0,7045 \mathrm{~S}= \pm 2 \sqrt{\frac{0,7045(1-0,7045)}{220}} \\
& 0,7045 \mathrm{~S}= \pm 2 \sqrt{\frac{0,7045(0,2955)}{220}} \\
& 0,7045 \mathrm{~S} \approx \pm 0,06 \\
& \mathrm{~S} \approx \pm \frac{0,06}{0,7045} \approx \pm 0,085 \approx 8,5 \%
\end{aligned}
$$

Karena $\pm 8,5 \%$ berada dibawah $10 \%$ dari tingkat ketelitian yang diinginkan, maka jumlah pengamatan telah mencukupi. 
Tabel 2. Waktu Baku Operator "A"

\begin{tabular}{|c|c|c|c|c|c|c|c|c|c|c|c|c|}
\hline \multirow{2}{*}{ No } & \multirow{2}{*}{ 氶 } & \multirow{2}{*}{ 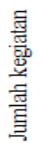 } & \multicolumn{2}{|c|}{$\begin{array}{c}\text { Barang yang } \\
\text { dihasilkan }\end{array}$} & \multirow{2}{*}{ 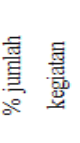 } & \multirow{2}{*}{ 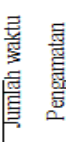 } & \multirow{2}{*}{ 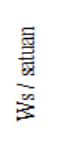 } & \multirow{2}{*}{ P } & \multirow{2}{*}{ 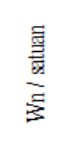 } & \multirow{2}{*}{$\begin{array}{c}\mathrm{i} \\
(\%)\end{array}$} & \multirow{2}{*}{$\frac{\text { 善 }}{\text { 竞 }}$} & \multirow{2}{*}{ 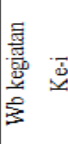 } \\
\hline & & & Jumlah & satuan & & & & & & & & \\
\hline 1 & 1 & 38 & 3.400 & Doos & 17,27 & 342 & 0,100 & 1,07 & 0,107 & 17 & 0,129 & 4,92 \\
\hline 2 & 2 & 34 & 2.760 & Doos & 15,45 & 306 & 0,110 & 1,15 & 0,127 & 22 & 0,163 & 5,55 \\
\hline 3 & 3 & 33 & 2.600 & Doos & 15 & 297 & 0,114 & 1,26 & 0,143 & 21 & 0,182 & 6,01 \\
\hline 4 & 4 & 32 & 640 & Doos & 14,54 & 288 & 0,45 & 1,06 & 0,477 & 17 & 0,574 & 18,39 \\
\hline 5 & 5 & 18 & 2.600 & Doos & 8,18 & 144 & 0,055 & 1,29 & 0,071 & 20 & 0,089 & 1,61 \\
\hline 6 & 6 & 65 & - & & 29,54 & 585 & - & - & - & - & - & - \\
\hline & & & & & 100 & 1962 & 0,83 & & 0,927 & & 1,139 & 36,49 \\
\hline
\end{tabular}

Beban kerja operator "A" dapat diketahui melalui perhitungan berikut :

Beban kerja $=\frac{\Sigma \text { Wb kegiatan }}{\Sigma \text { waktu pengamatan produktif }} \times 100 \%$

Dimana :

Jumlah waktu pengamatan produktif $=1962$

Maka beban kerja operator " $\mathrm{A}$ " adalah

$\frac{36,49 \text { menit }}{1962 \text { menit }} \times 100 \%=1,86 \%$

B. Hasil Persentase Produktif Operator "B".

Tabel 3. Persentase Produktif Operator "B".

\begin{tabular}{|c|c|c|c|c|c|c|}
\hline \multirow{2}{*}{ kegiatan } & \multicolumn{5}{|c|}{ Frekuensi pada hari - } & \multirow{2}{*}{ jumlah } \\
\hline & 1 & 2 & 3 & 4 & 5 & \\
\hline produktif & 27 & 33 & 36 & 29 & 28 & 153 \\
\hline Non produktif & 17 & 11 & 8 & 15 & 16 & 67 \\
\hline jumlah & 44 & 44 & 44 & 44 & 44 & 220 \\
\hline $\begin{array}{l}\text { Persentase } \\
\text { produktif }\end{array}$ & $61 \%$ & $75 \%$ & $82 \%$ & $66 \%$ & $64 \%$ & \\
\hline
\end{tabular}

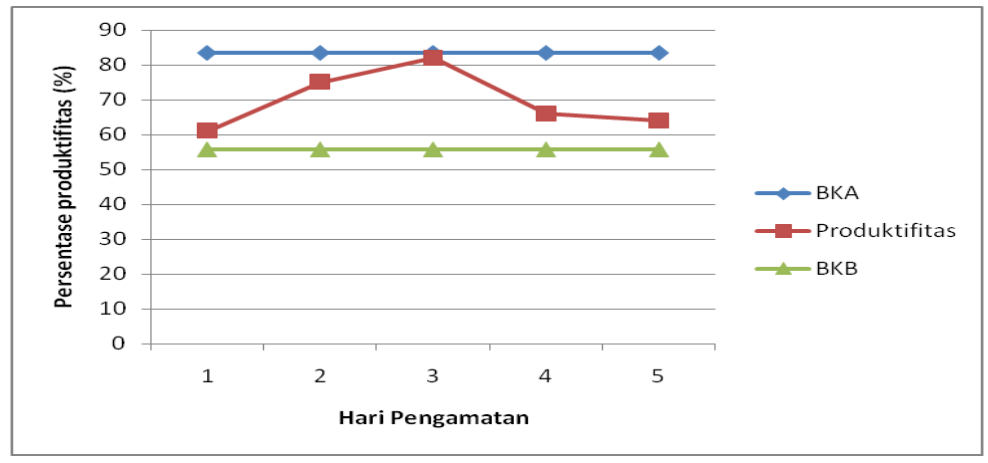

Gambar 3. Peta Kendali Produktif Operator "B"

Data persentase produktif seluruhnya terdapat diantara batas kendali atas ( BKA) dan batas kendali bawah ( BKB ), yang menandakan adanya keseragaman data.

Jumlah pengamatan yang diperlukan untuk tingkat ketelitian $10 \%$ dan keyakinan $95 \%$ dik etahui melalui rumus berikut :

$$
\mathrm{N}=\frac{400(1-p)}{p}
$$




$$
\begin{aligned}
& \text { Dimana }: \mathrm{p}=\frac{153}{220} \times 100 \%=69,54 \% \\
& \text { Maka }: \mathrm{N}=\frac{400(1-0,6954)}{0,6954}=175 \text { kali kunjungan }
\end{aligned}
$$

Jumlah pengamatan yang diperlukan untuk mengamati kegiatan operator " $B$ " verifikasi uang logam dibagian perhitungaan dan pembungkusan awal sebanyak 175 kali kunjungan, sedangkan jumlah pengamatan yang telah dilakukan sebanyak 220 kali kunjungan. Hal ini menandakan bahwa jumlah pengamatan telah mencukupi, sebab sudah melebihi jumlah pengamatan yang diperlukan.

Setelah pengamatan telah mencukupi, selanjutnya menentukan apakah hasil pengamatan tersebut sesuai dengan tingkat ketelitian yang diinginkan melalui perhitungan berikut :

$$
\begin{aligned}
& \mathrm{S} p=2 \sqrt{\frac{p(1-p)}{N}} \\
& 0,6954 \mathrm{~S}= \pm 2 \sqrt{\frac{0,6954(1-0,6954)}{220}} \\
& 0,6954 \mathrm{~S}= \pm 2 \sqrt{\frac{0,6954(0,3046)}{220}} \\
& 0,6954 \mathrm{~S} \approx \pm 0,06 \\
& \mathrm{~S} \approx \pm \frac{0,06}{0,6954} \approx \pm 0,086 \approx 8,6 \%
\end{aligned}
$$

\begin{tabular}{|c|c|c|c|c|c|c|c|c|c|c|c|c|}
\hline \multirow{2}{*}{ No } & \multirow{2}{*}{ 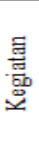 } & \multirow{2}{*}{ 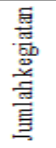 } & \multicolumn{2}{|c|}{$\begin{array}{c}\text { Barang yang } \\
\text { dihasilkan }\end{array}$} & \multirow{2}{*}{ 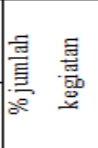 } & \multirow{2}{*}{ 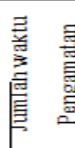 } & \multirow{2}{*}{ 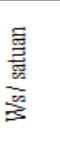 } & \multirow{2}{*}{$\mathbf{P}$} & \multirow{2}{*}{ 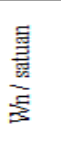 } & \multirow{2}{*}{$\begin{array}{c}\mathrm{i} \\
(\%)\end{array}$} & \multirow{2}{*}{ 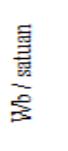 } & \multirow{2}{*}{ 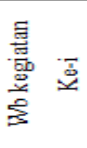 } \\
\hline & & & Jumlah & satuan & & & & & & & & \\
\hline 1 & 1 & 36 & 3360 & Doos & 16,36 & 324 & 0,09 & 1,07 & 0,10 & 17 & 0,12 & 4,47 \\
\hline 2 & 2 & 34 & 3040 & Doos & 15,45 & 306 & 0,10 & 1,15 & 0,11 & 22 & 0,14 & 5,04 \\
\hline 3 & 3 & 32 & 2960 & Doos & 14,54 & 288 & 0,09 & 1,26 & 0,12 & 21 & 0,15 & 4,96 \\
\hline 4 & 4 & 31 & 320 & Doos & 14,09 & 279 & 0,87 & 1,06 & 0,92 & 17 & 1,11 & 34,51 \\
\hline 5 & 5 & 20 & 2960 & Doos & 9,09 & 160 & 0,05 & 1,29 & 0,06 & 20 & 0,08 & 1,74 \\
\hline 6 & 6 & 67 & - & & 30,45 & 603 & - & - & - & - & - & - \\
\hline & & 220 & & & 100 & 1960 & 1,22 & & 1,33 & & 1,62 & 50,75 \\
\hline
\end{tabular}

Karena $\pm 8,6 \%$ berada dibawah $10 \%$ dari tingkat ketelitian yang diinginkan, maka jumlah pengamatan telah mencukupi.

Tabel 4. Waktu Baku Operator "B"

Beban kerja operator "B" dapat diketahui melalui perhitungan berikut :

Beban kerja $=\frac{\Sigma \text { Wb kegiatan }}{\Sigma \text { waktu pengamatan produktif }} \times 100 \%$

Dimana :

Jumlah waktu pengamatan produktif $=1960$

Maka beban kerja operator "B" adalah

$\frac{50,75 \text { menit }}{1960 \text { menit }} \times 100 \%=2,58 \%$ 
C. Hasil Persentase Produktif Operator "C".

Tabel 5. Persentase Produktif Operator "C".

\begin{tabular}{|c|c|c|c|c|c|c|}
\hline \multirow{2}{*}{ kegiatan } & \multicolumn{5}{|c|}{ Frekuensi pada hari - } & \multirow{2}{*}{ jumlah } \\
\hline & 1 & 2 & 3 & 4 & 5 & \\
\hline produktif & 34 & 33 & 32 & 35 & 27 & 161 \\
\hline Non produktif & 10 & 11 & 12 & 9 & 17 & 59 \\
\hline jumlah & 44 & 44 & 44 & 44 & 44 & 220 \\
\hline $\begin{array}{l}\text { Persentase } \\
\text { produktif }\end{array}$ & $77 \%$ & $75 \%$ & $72 \%$ & $79 \%$ & $61 \%$ & \\
\hline
\end{tabular}

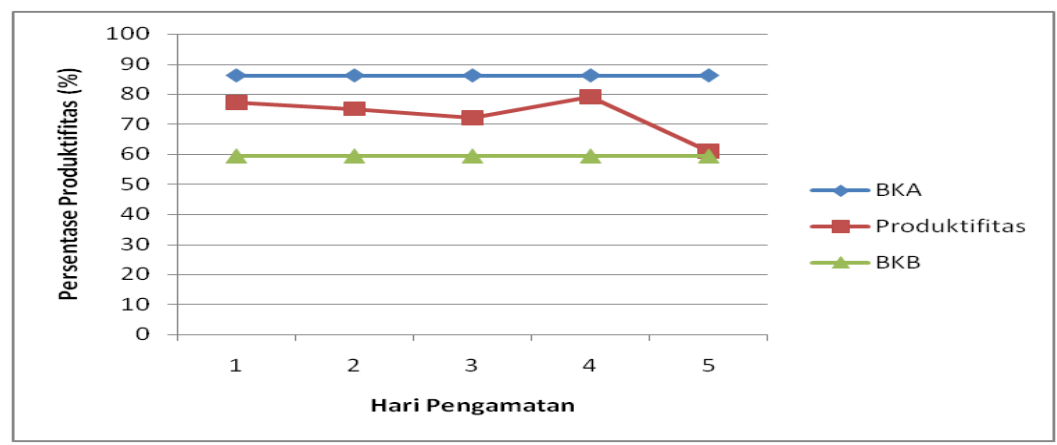

Gambar 4. Peta Kendali Produktif Operator "C"

Data persentase produktif seluruhnya terdapat diantara batas kendali atas ( BKA ) dan batas kendali bawah ( BKB ), yang menandakan adanya keseragaman data.

Jumlah pengamatan yang diperlukan untuk tingkat ketelitian $10 \%$ dan keyakinan $95 \%$ diketahui melalui rumus berikut :

$$
\begin{aligned}
& \mathrm{N}=\frac{400(1-p)}{p} \\
& \text { Dimana }: \mathrm{p}=\frac{161}{220} \times 100 \%=73,18 \% \\
& \text { Maka }: \mathrm{N}=\frac{400(1-0,7318)}{0,7318}=147 \text { kali kunjungan }
\end{aligned}
$$

Jumlah pengamatan yang diperlukan untuk mengamati kegiatan operator " $C$ " verifikasi uang logam dibagian perhitungaan dan pembungkusan awal sebanyak 147 kali kunjungan, sedangkan jumlah pengamatan yang telah dilakukan sebanyak 220 kali kunjungan. Hal ini menandakan bahwa jumlah pengamatan telah mencukupi, sebab sudah melebihi jumlah pengamatan yang diperlukan.

Setelah pengamatan telah mencukupi, selanjutnya menentukan apakah hasil pengamatan tersebut sesuai dengan tingkat ketelitian yang diinginkan melalui perhitungan berikut :

$$
\begin{aligned}
& \mathrm{S} p=2 \sqrt{\frac{p(1-p)}{N}} \\
& 0,7318 \mathrm{~S}= \pm 2 \sqrt{\frac{0,7318(1-0,7318)}{220}} \\
& 0,7318 \mathrm{~S}= \pm 2 \sqrt{\frac{0,7318(0,2682)}{220}} \\
& 0,7318 \mathrm{~S} \approx \pm 0,06 \\
& \mathrm{~S} \approx \pm \frac{0,06}{0,7318} \approx \pm 0,081 \approx 8,1 \%
\end{aligned}
$$


Karena $\pm 8,1 \%$ berada dibawah $10 \%$ dari tingkat ketelitian yang diinginkan, maka jumlah pengamatan telah mencukupi.

Tabel 6. Waktu Baku Operator "C"

\begin{tabular}{|c|c|c|c|c|c|c|c|c|c|c|c|c|}
\hline \multirow{2}{*}{ No } & \multirow{2}{*}{ 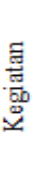 } & \multirow{2}{*}{ 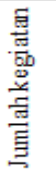 } & \multicolumn{2}{|c|}{$\begin{array}{c}\text { Barang yang } \\
\text { dihasilkan }\end{array}$} & \multirow{2}{*}{ 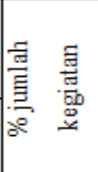 } & \multirow{2}{*}{ 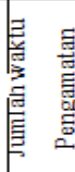 } & \multirow{2}{*}{ 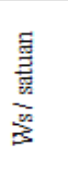 } & \multirow{2}{*}{$P$} & \multirow{2}{*}{ 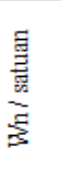 } & \multirow{2}{*}{$\begin{array}{c}\mathrm{i} \\
(\%)\end{array}$} & \multirow{2}{*}{ 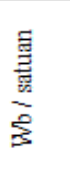 } & \multirow{2}{*}{ 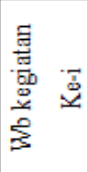 } \\
\hline & & & Jumlah & satuan & & & & & & & & \\
\hline 1 & 1 & 40 & 3.840 & Doos & 18,18 & 360 & 0,09 & 1,07 & 0,10 & 17 & 0,12 & 4,83 \\
\hline 2 & 2 & 36 & 3.240 & Doos & 16,36 & 324 & 0,1 & 1,15 & 0,11 & 22 & 0,14 & 5,3 \\
\hline 3 & 3 & 33 & 2.640 & Doos & 15 & 297 & 0,11 & 1,26 & 0,14 & 21 & 0,17 & 5,92 \\
\hline 4 & 4 & 33 & 600 & Doos & 15 & 297 & 0,49 & 1,06 & 0,52 & 17 & 0,63 & 20,86 \\
\hline 5 & 5 & 19 & 2.640 & Doos & 8,63 & 152 & 0,05 & 1,29 & 0,07 & 20 & 0,09 & 1,76 \\
\hline 6 & 6 & 59 & - & & 26,81 & 531 & - & - & - & - & - & - \\
\hline & & 220 & & & 100 & 1961 & 0,85 & & 0,95 & & 1,17 & 38,68 \\
\hline
\end{tabular}

Beben kerja operator "C" dapat diketahui melalui perhitungan berikut :

Beban kerja $=\frac{\Sigma \text { Wb kegiatan }}{\Sigma \text { waktu pengamatan produktif }} \times 100 \%$

Dimana :

Jumlah waktu pengamatan produktif $=1961$

Maka beban kerja operator " $\mathrm{C}$ " adalah

$\frac{38,68 \text { menit }}{1961 \text { menit }} \times 100 \%=1,97 \%$

Setelah beban kerja ketiga operator verifikasi diketahui, maka hasil akhir pengolahan data dari ketiga operator dapat disajikan pada tabel VII dibawah ini :

Tabel 7. Hasil Akhir Pengolahan Data Operator

\begin{tabular}{|c|c|c|c|c|}
\hline \multirow{2}{*}{ No } & \multirow{2}{*}{ Uraian } & \multicolumn{3}{|c|}{ Operator } \\
\hline & & A & B & $\mathrm{C}$ \\
\hline 1 & Hari Pengamatan & Senin $a / d$ jumat & Senin $a / d$ jumat & Senin $\mathrm{a} / \mathrm{d}$ jumat \\
\hline 2 & $\begin{array}{c}\text { Tanggal } \\
\text { pengamatan }\end{array}$ & $\begin{array}{c}03 \mathrm{a} / \mathrm{d} 07 \\
\text { olstober } 2016\end{array}$ & $\begin{array}{c}03 \mathrm{a} / \mathrm{d} 07 \\
\text { olktober } 2016\end{array}$ & $\begin{array}{c}03 \mathrm{a} / \mathrm{d} 07 \text { olktober } \\
2016\end{array}$ \\
\hline 3 & $\begin{array}{l}\text { Kegiatan } \\
\text { produktif }\end{array}$ & $70,4 \%$ & $69,54 \%$ & $73,18 \%$ \\
\hline 4 & $\begin{array}{c}\text { Jumlah } \\
\text { pengamatam yang } \\
\text { diperluksan }\end{array}$ & $\begin{array}{c}168 \mathrm{ksali} \\
\text { kunjungan }\end{array}$ & $\begin{array}{c}175 \mathrm{ksali} \\
\text { kunjungan }\end{array}$ & $\begin{array}{c}147 \text { kali } \\
\text { kunjungan }\end{array}$ \\
\hline 5 & $\begin{array}{l}\text { Pengujian tingkst } \\
\text { ketelitian } \\
\text { pengamatan }\end{array}$ & $=8,5 \%$ & $=8,6 \%$ & $=8,1 \%$ \\
\hline 6 & $\begin{array}{l}\text { Waktu kegiatan } \\
\text { produltif }\end{array}$ & $\begin{array}{c}09.05-10.25 \\
\text { (selasa dan } \\
\text { lcamis, } 04 \text { dan } \\
06-10-2016 \text { ) } \\
10.35-11.55 \\
\text { (senin, 03-10- } \\
2016) \\
13.05-15.15 \\
\text { (rabu, } 05-10- \\
2016)\end{array}$ & $\begin{array}{c}10.35-11.55 \\
(\mathrm{rabun}, 5-10- \\
2016)\end{array}$ & $\begin{array}{c}10.35-11.55 \\
(\mathrm{rabu}, 5-10-2016)\end{array}$ \\
\hline 7 & $\begin{array}{l}\text { Waktu } \\
\text { pengamatan } \\
\text { produluktif }\end{array}$ & 1962 menit & 1960 menit & 1961 menit \\
\hline 8 & Nilai beban kerja & $1,86 \%$ & $2,58 \%$ & $1,97 \%$ \\
\hline
\end{tabular}

Berdasarkan hasil pengolahan data yang diperoleh bahwa besaran beban kerja operator verifikasi uang logam $\mathrm{A}, \mathrm{B}$, dan $\mathrm{C}$ adalah sebesar 1,86\%, 2,58\% dan 1,97\%. Nilai tersebut didapatkan berdasarkan banyaknya kegiatan produktif yang telah dilakukan serta barang yang dihasilkan. Semakin sering kegiatan produktif dilakukan akan semakin besar pula nilai beban pekerjaan yang menjadi tanggung jawabnya. 


\section{KESIIMPULAN DAN SARAN}

\section{Kesimpulan}

Berdaasarkan pengamatan dan pengolahan data terhadap tiga orang operator verifikasi uang logam di Perum Peruri, diperoleh kesimpulan sebagai berikut :

1. Melalui pengukuran work sampling dapat diketahui bahwa nilai beban kerja operator verifikasi uang logam adalah sebesar 1,86\%, 2,58\% dan 1,97\%.

2. Faktor yang mempengaruhi beban kerja operator diantaranya :
a. Banyaknya kegiatan produktif yang dilakukan.
b. Jumlah barang yang dihasilkan
c. Tingkat kebutuhan penyesuaian dan kelonggaran
d. Cara dan kondisi kerja

3. Usaha meningkatkan kualitas kerja operator dapat dimulai dari diri individu operator dan diiringi dengan oleh peningkatan kualitas kerja operator dari individu yang lainnya. Peningkatan kualitas diorientasikan pada pemenuhan fisiologis dan psikologis yang selalu membutuhkan motivasi dan kepuasan kerja. Perbaikan tersebut dimanfaatkan untuk kepentingan organisasi dan tenaga kerja.

\section{Saran} peruri adalah

Beberapa saran yang dapat dipertimbangkan guna meningkatkan produktifitas di perum

1. Meningkatkan kerja sama antar operator sehingga menciptakan suasana lingkungan kerja yang enak, nyaman, aman dan sehat.

2. Sebaiknya pembagian tugas pekerjaan oleh atasan pada para bawahannya dilakukan lebih merata dan adil. Kondisi tersebut harus lebih diperhatikan mengingat konflik kerja antara atasan dan bawahan memiliki kontribusi paling besar dalam mempengaruhi motivasi dan kinerja pegawai.

3. Membuat Alat Bantu pengangkat bak yang berisi roll dengan sistem hidrolik atau conveyor sehingga membuat beban kerja menjadi lebih ringan. Karena bekerja mengangkat beban kerja secara terus menerus dan berulang - ulang maka akan terjadinya fatique yang menyebabkan para pegawai menjadi merasakan kejenuhan, lelah, menurunnya daya konsentrasi, timbulnya rasa kantuk dan dapat menyebabkan masalah kesehatan.

4. Keterbatasan peneliti menjadi salah satu kendala dalam mengembangkan analisis beban kerja pegawai, sehingga banyak kekurangan - kekurangan lebih lanjut yang serupa untuk mendukung upaya - upaya dalam menganalisis beban kerja pegawai.

\section{DAFTAR RUJUKAN}

Mufidah, E. (2002). Menentukan Beban Kerja Karyawan Kasir Menggunakan Metode Uji Petik Pekerjaan. Jakarta: Institut Sains dan Teknologi Al-Kamal.

Pranoto, L. H., \& Retnowati. (2015). Analisis Beban Kerja Sumner Daya Manusia Perusahaan. Jakarta: PPM Manajemen.

Sutalaksana, I. A., \& Tjakraatmadja, J. (2006). Teknik Tata Cara Kerja. Bandung: Departemen Teknik Industri Institut Teknologi Bandung.

Widjaja, D. C. (2013). Analisis Beban Kerja (Workload) dan Kinerja Karyawan Housekeeping di Hotel X. Surabaya: Program Manajemen Perhotelan, Fakultas Ekonomi, Universitas Kristen Petra. 